\title{
A Cytological Study of Anther and Pollen Development in Chinquapin (Castanea henryi)
}

\author{
Weiping Zhong, Zhoujun Zhu, Fen Ouyang, Qi Qiu, Xiaoming Fan, \\ and Deyi Yuan \\ Central South University of Forestry and Technology, Changsha 410004, \\ Hunan, China; Key Laboratory of Non-Wood Forest Products of State \\ Forestry Administration; Key Laboratory of Cultivation and Protection for \\ Non-Wood Forest Trees, Ministry of Education; and Cooperative Innovation \\ Center of Cultivation and Utilization for Non-Wood Forest Trees of Hunan \\ Province
}

Additional index words. staminate catkin, morphology, reproductive organs, starch, lipid

\begin{abstract}
The normal development of anthers and the formation of functional pollen are the prerequisites for successful pollination and fertilization. In this study, we observed dynamic changes in inflorescence and anther development in the chinquapin (Castanea henryi) using stereomicroscopy, light microscopy, and transmission electron microscopy. We found that cytokinesis during meiosis in microsporocytes was of the simultaneous type, and that the tetrads were mainly tetrahedral. Mature pollen grains contained two cells with three germ pores. The anther wall was of the basic type and composed of epidermis, endothecium, middle layers, and tapetum. Mature anthers had no middle layer and tapetum. The tapetum was of the glandular type. At the early microspore stage, a large number of starch granules appeared in the endothecium, which was deformed at the late microspore stage. Lipid droplets appeared in tapetum during the early microspore stage, and a few lipid droplets were still found during tapetum degeneration. The mature pollen accumulated a large amount of starch and lipids. These findings demonstrated that the anther wall provides nutrients and protection for pollen development. There is relatively stable correspondence between the external morphological characteristics of male flowers and internal structure of anther development.
\end{abstract}

Chinquapin [Castanea henryi (Skan) Rehd. \& E.H. Wilson, Fagaceae] is one of the most economically important nonwood forest species in the south of China. This chestnut species is widely planted in the Fujian, Zhejiang, and Hunan provinces (Li et al., 2019; Xiong et al., 2018). Its nut contains large amounts of starch, protein, and soluble sugars, and relatively low amounts of fat (Fan et al., 2015). Because of its preferred taste and health benefits, chinquapin is one of the most commonly consumed nuts in China (Fan et al., 2015). Long-term cultivation of the chinquapin has shown that low yield is common because of the low ratios of female and male flowers (Fan et al., 2017; Zhu et al., 2016).

\footnotetext{
Received for publication 14 Feb. 2020. Accepted for publication 3 Apr. 2020.

Published online 15 May 2020.

This study was supported by the National Natural Science Foundation of China (grant no. 31870674) and the Natural Science Foundation of Hunan Province (grant no. 2019JJ50983).

W.Z. and Z.Z. contributed equally.

X.F. and D.Y. are the corresponding authors. E-mail: fan_xiaoming001@163.com or yuan_deyi2014@ 126.com.

This is an open access article distributed under the CC BY-NC-ND license (https://creativecommons. org/licenses/by-nc-nd/4.0/).
}

The stamen is the male reproductive organ of angiosperms. The development of anthers, the parts of the stamen where pollen is produced, is a delicate and complex process that includes the formation of the anther wall tissue (with a protective function) and pollen (with a reproductive function). From the outer to the inner layers, the anther wall includes epidermis, endothecium, middle layer, and tapetum. During anther development, different anther wall cell layers undergo different developmental stages, such as vacuolation of epidermal and endothecial cells (Gao et al., 2015; Zou et al., 2013) and degeneration of middle layer cells and tapetal cells (Muniraja et al., 2018; Zou et al., 2013). Some plant species display remarkable phenomena, such as nonsynchronous development of the middle layer and tapetum and delayed degeneration of the tapetum (Kim et al., 2016). Different pollen development characteristics, such as the duration of each stage of pollen development, cytokinesis during meiosis in microspore mother cells, arrangement of microspores in tetrads, and the degree of pollen development at flowering, vary among plant species (Borg et al., 2009; Brewbaker, 1967; Pacini, 1996; Wilson and Zhang, 2009). A prominent feature of pollen development in angiosperms is the accumulation of large amounts of nutrients before germination, usually starch or lipid droplets. These changes in the nutritional components are closely related to pollen development. The duration and type of nutrient accumulation in anthers vary among species. Nevertheless, the synthesis of these nutrients and their transportation to anthers remain unclear, and more research of this topic is needed.

However, little research has been performed regarding the development of male reproductive organs in chinquapin. In the present study, we observed the anther structure and distribution of starches and lipids in the anther to investigate the anther development characteristics of this species. We observed and recorded the correlation between anther and male inflorescence development, which could serve as baseline knowledge for future investigations of chinquapin reproduction.

\section{Materials and Methods}

Plant materials. Staminate catkins of Castanea henryi 'Huali 4' growing in Rucheng County (Hunan Province, China, lat. $25^{\circ} 33^{\prime} 43^{\prime \prime} \mathrm{N}$, long. $113^{\circ} 45^{\prime} 08^{\prime \prime} \mathrm{E}$ ), at $\approx 765 \mathrm{~m}$ a.s.l., were collected for analysis. Inflorescences were obtained from a 10-yearold tree selected for its good health. Ten inflorescences were collected every day from the middle part of the branch from early April to late May in 2015, 2016, and 2017. The samples were photographed with a digital camera. Morphological characteristics of male flower clusters from the middle of the inflorescence were observed under a microscope (SZX16; Olympus, Tokyo, Japan).

Scanning electron microscopy (SEM). The materials were mounted on SEM stubs, coated with gold-palladium, and examined and photographed with a scanning electron microscope (SEM-6380LV; JEOL, Tokyo, Japan) (Mert, 2010).

Light microscopy. Samples were prefixed in FAA (70\% ethyl alcohol: glacial acetic acid: formalin $=90: 5: 5 \mathrm{v} / \mathrm{v}$ ) and stored at $4{ }^{\circ} \mathrm{C}$ before sectioning. The anther material was treated with dehydration through an ethylalcohol series, transparency, and embedded in paraffin. Embedded tissues were sectioned to a thickness of $6 \mu \mathrm{m}$ using a Leica RM2235 rotary microtome and stained with Safranin$\mathrm{O} /$ Fast Green. Samples were examined and photographed under a light microscope (DMi8; Leica, Wetzlar, Germany).

Semi-thin tissue sections and transmission electron microscopy. Anthers at different developmental stages were cut off and immediately fixed in $2.5 \%$ glutaraldehyde in $0.1 \mathrm{M}$ phosphate buffer ( $\mathrm{pH} 7.2$ ) for $4 \mathrm{~h}$ at $4{ }^{\circ} \mathrm{C}$ (Wei et al., 2015). After washing with $0.1 \mathrm{M}$ phosphate buffer, the anthers were post-fixed in $1 \%$ osmium tetroxide $\left(\mathrm{OsO}_{4}\right)$ in the aforementioned buffer solution for $8 \mathrm{~h}$ at $4{ }^{\circ} \mathrm{C}$. The samples were then dehydrated by passing through a graded series of acetone, washed with $0.1 \mathrm{M}$ phosphate buffer, and embedded in EMbed 812 resins. The tissue block was cut into $1-\mu \mathrm{m}$ semi-thin sections with an Ultracut R microtome (EM UC7; Leica, Berlin, Germany). After staining with $0.5 \%$ toluidine 
blue, the specific stage of anther development was examined under an optical microscope (BX-51; Olympus, Tokyo, Japan). Samples at typical specific developmental stages were cut into ultrathin sections $(6 \mathrm{~nm})$, and the sections were double-stained with uranyl acetate and lead citrate aqueous solution (Yang et al., 2018). Selected sections at different developmental stages were photographed with a transmission electron microscope (HT7700; HITACHI, Tokyo, Japan).

\section{Results}

\section{Staminate catkin and anther size development}

The chinquapin is an andromonoecious plant with two types of catkins: bisexual catkins, located near the apex, and staminate catkins, which develop near the base of the flower branches (Fig. 1A). We studied staminate catkins and male flowers because they flowered synchronously with female flowers. Male flower clusters typically consisted of three to five flowers surrounded by an involucral bract. Individual male flowers were enclosed in a dense tomentose perianth. Anthers were enclosed in perianth, and their development varied depending on the arrangement of flowers.

Anther development lasted from midApril to early May (Table 1). To correlate the anther developmental stages with growth stages, we observed the growth dynamics of staminate catkins and clusters and measured the length and width of anthers. The staminate catkin lengthened until the male flower opened, and the color of the flower changed from dark green to light green (Fig. 1D-U). During growth, the perianth became separated, with filaments and transparent anthers becoming indistinctly visible at $\approx 22$ Apr. (Table 1, Fig. 1). In early May, the male flowers opened, presenting yellowish mature anthers. The length and width of individual anthers varied during their development (Table 1). At the early microspore stage, anther size increased quickly. At the early two-cell pollen stage, anthers barely grew in size. Remarkably, at maturity, the anther length and width increased by $63.67 \%$ and $73.24 \%$, respectively, compared with anthers in the microsporocyte stage.

\section{Anther wall and pollen development}

The anther wall and pollen development stages were examined. The developmental events were subsequently grouped into six stages: 1) microsporocyte stage; 2) tetrad stage; 3) early microspore stage; 4) late microspore stage; 5) early two-cell pollen stage; and 6) pollen maturation stage.

Microsporocyte stage. At the microsporocyte stage, the size of the microsporocyte in the anthers increased significantly and the anther chamber was formed (Fig. 2A-C). The
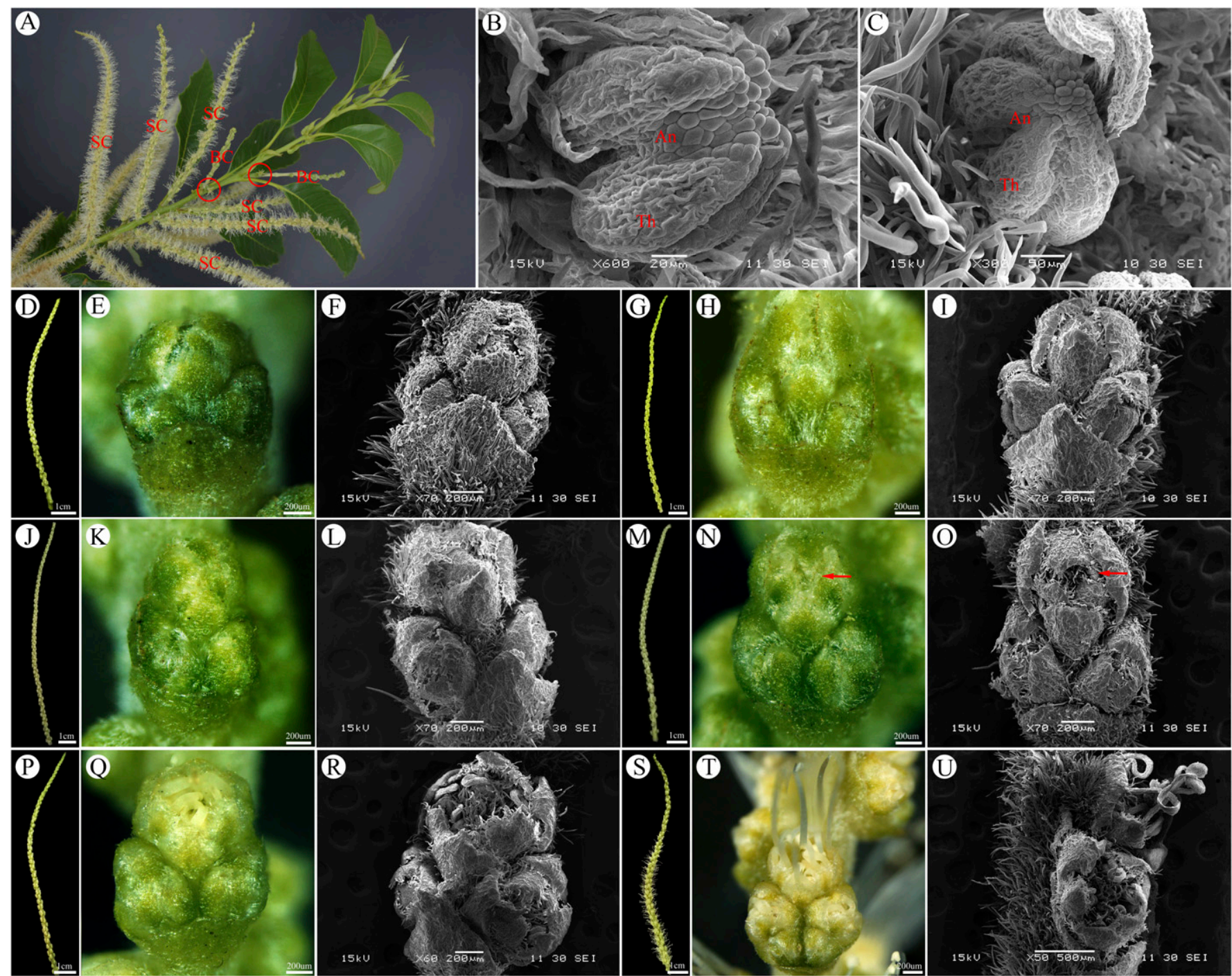

Fig. 1. Morphology of staminate catkins and flower clusters corresponding to the anther development period. (A) Morphological observation of the bearing branch in chinquapin. The red circle indicates the female flower. (B, C) The butterfly-shaped anthers. (D-F) The staminate catkin and male flower cluster at the microsporocyte stage. (G-I) The staminate catkin and male flower cluster at the tetrad stage. (J-L) The staminate catkin and male flower cluster at the early microspore stage. (M-O) The staminate catkin and male flower cluster at the late microspore stage. (P-R) The staminate catkin and male flower cluster at the early two-cell pollen stage. $(\mathbf{S}-\mathbf{U})$ The staminate catkin and male flower cluster at the pollen maturation stage. An $=$ anther; $\mathrm{BC}=$ bisexual catkin; $\mathrm{SC}=$ staminate catkin; $\mathrm{Th}=$ theca. 
Table 1. Major morphological stages during chinquapin anther and pollen development.

\begin{tabular}{|c|c|c|c|c|c|}
\hline & Stage & Time & $\begin{array}{l}\text { Anther length }(\mathrm{L}) \\
{[\mathrm{mean} \pm \mathrm{SE}(\mu \mathrm{m})]}\end{array}$ & $\begin{array}{l}\text { Anther width }(\mathrm{W}) \\
{[\mathrm{mean} \pm \mathrm{SE}(\mu \mathrm{m})]}\end{array}$ & Significant phenotype of the male inflorescence \\
\hline 1 & Microsporocyte stage & $4.11-4.12$ & $141.57 \pm 11.27$ & $136.71 \pm 15.49$ & $\begin{array}{l}\text { Staminate catkins are dark green; there is a clear outline } \\
\text { of single flowers }\end{array}$ \\
\hline 2 & Tetrad stage & $4.13-4.14$ & $158.25 \pm 9.85$ & $148.50 \pm 12.98$ & $\begin{array}{l}\text { The staminate catkin is elongated; the size of clusters } \\
\text { increases; the color is light green with some yellow }\end{array}$ \\
\hline 3 & Early microspore stage & $4.15-4.20$ & $192.92 \pm 19.84$ & $180.58 \pm 12.57$ & The staminate catkin is light green \\
\hline 4 & Late microspore stage & $4.21-4.24$ & $216.22 \pm 10.92$ & $210.11 \pm 9.68$ & $\begin{array}{l}\text { The individual perianth separates; filaments and } \\
\text { transparent anthers are indistinctly visible }\end{array}$ \\
\hline 5 & Early two-cell pollen stage & $4.25-4.28$ & $245.00 \pm 7.17$ & $223.00 \pm 9.59$ & $\begin{array}{l}\text { Staminate catkin reaches the maximum length; } \\
\text { individual flowers open near the base of inflorescence; } \\
\text { filaments and anthers are more exposed }\end{array}$ \\
\hline 6 & Pollen maturation stage & $4.29-5.4$ & $245.25 \pm 4.03$ & $223.75 \pm 10.63$ & $\begin{array}{l}\text { The staminate catkin is yellowish; a few filaments are } \\
\text { protruded; the anther is light yellow }\end{array}$ \\
\hline
\end{tabular}

microsporocytes were distributed through the chamber and large gaps appeared between cells. Microsporocyte nuclei were large and easy to identify. The surface of the microspore mother cell developed an uneven, thickened callose wall. At this stage, the anther wall formed a typical four-layer cell structure. The outermost layer was the epidermis, which was easily distinguished from the rest of the layers because of its position, and it was composed of large cells, some of which were highly vacuolated. The epidermis was adjacent to the endothecium, with the latter separating the epidermis and the middle layer. Cells in the endothecium were large and contained considerable vacuoles, whereas the cells in the middle layer were flat and long. The innermost layer was composed of tapetal cells that were large and had multiple nuclei.

Tetrad stage. After meiosis, microspore mother cells each formed four haploid spores that were mainly tetrahedral and enclosed in the common callose wall (Fig. 2E-G). After toluene blue staining, the callose wall of the tetrad was stained deeply, whereas the microspores were less stained (Fig. 2G). At this stage, the epidermis showed few differences compared to those observed at the microsporocyte stage. However, in the endothecium, the vacuolization increased and the cytoplasmic content of endothecial cells decreased (Fig. 2F and G). The cells of the middle layer became thinner in the radial tangential direction and some vacuoles appeared in the cells. Remarkably, the tapetal cells began to show a degeneration trend, with more vacuoles and scattered organelles (Fig. 2F-H). The inner tangential wall and the radial wall of the tapetal cell degraded and some Ubisch bodies appeared on the surface of the plasma membrane (Fig. 2H).

Early microspore stage. With the dissolution of the tetrad callose wall, microspores were released and free microspores were formed. A large nucleus was located in the center of the microspore, which is why this stage is also called the mononuclear median period of pollen (Fig. 2I-K). The size of the early microspores rapidly increased and the cytoplasm began to vacuolate. However, we observed a clearly visible and relatively complete pollen wall with three visible germ pores (Fig. 2L). The epidermal cells and middle layer cells did not change much at this stage relative to previous stages. Notably, some chloroplasts with a regular shape and round chloroplast starch granules were distributed in the endothecial cells (Fig. 2L). In addition, at this stage, the tapetal cells began to degenerate and more lipids appeared in the cytoplasm (Fig. 2L).

Late microspore stage. With the development of microspores, a large vacuole gradually emerged in the cytoplasm, pushing the nucleus and cytoplasm to the periphery and making the microspores distinctly polar. This stage is also known as the uninucleate stage of pollen development (Fig. 2M-O). The pollen wall thickened and the germ pores became more visible. At this stage, the anther wall showed some characteristic changes. The endothecial cells were significantly enlarged and formed a band-like structure (Fig. 2O). The chloroplasts degraded and the starch grains showed obvious deformation (Fig. 2P). Cells of the middle layer became thinner in the radial tangential direction, after which they began to disintegrate. The tapetal cells adjacent to the middle layer cells contracted and degenerated, and Ubisch bodies were detected in the locule (Fig. 2O and $\mathrm{P}$ ).

Early two-cell pollen stage. As the microspore nucleus moved to the edge of the cell, the large vacuole began to contract. Later, the microspores underwent asymmetric mitosis to form a structure called two-cell pollen that consisted of a small reproductive cell and a larger vegetative cell (Fig. 2Q-S). They were isolated by a discontinuous cell plate (Fig. 2T). The reproductive cell changed its shape from lenticular to round, and it slowly separated from the pollen wall and was released in the cytoplasm of the vegetative cell (Fig. 2T). However, the middle layer cells almost completely disappeared (Fig. 2R and $\mathrm{S})$. The tapetal cells continued to degenerate and cytoplasm decreased significantly (Fig. 2R and S).

Pollen maturation stage. On the day of flowering, the pollen matured and the shape of its cross-section was close to circular (Fig. 2U-X). The wall of the mature pollen was clearly divided into two layers, the outer and the inner wall. The inner wall was thick in the aperture zone and thin in the nonaperture zone (Fig. 2X). No outer wall layer was observed in the aperture zone. Many starch and lipids accumulated in the pollen (Fig. 2X). At this stage, the anther wall tissue comprised only one epidermis (outside layer) and one endothecium (inside layer) (Fig. 2UW). Pollen was of the two-cell pollen type, consisting of a vegetative cell and a reproductive cell. The cytoplasm of the vegetative cell was thick and contained various organelles, starch, and lipids. However, the reproductive cell was small and had a large nucleus and less cytoplasm. It contained organelles such as the Golgi apparatus, endoplasmic reticulum, and mitochondria with a complete structure, but no plastids were found (Fig. 2X).

\section{Discussion}

The anther wall of the chinquapin was of the basic type and consisted of an epidermis, endothecium, middle layer, and tapetum. These layers were adjacent to each other, but they differed greatly in shape, structure, and function. These results are consistent with the structures reported for many angiosperms (Fan et al., 2015; Gao et al., 2015; Zhang et al., 2019; Zou et al., 2013). Epidermal and endothecial cells were present at all stages of anther development, and their volume and degree of vacuolation increased gradually. Previous research showed that the epidermis could prevent water loss from anthers and provide structural support for the anther wall along with the endothecium (Goldberg et al., 1993). At the stage of anther maturity, the endothecium reached its maximum size and its cell wall thickened from the inner tangential wall to the outer and upward wall. This uneven thickening of the endothecium promoted the rupture of the stomium (Mitsuda et al., 2005; Scott et al., 2004; Yang et al., 2007).

In the present study, the cells of the middle layer of the chinquapin anthers were flat and long. Starting with meiosis, the middle layer cells began to change, becoming flatter and decreasing their reserve substance levels. Then, they tended to gradually disintegrate and were absorbed, disappearing completely at the pollen maturation stage. It has been reported that there are usually one to four middle layers in anther walls, but there are no middle layers in mature anthers. In 

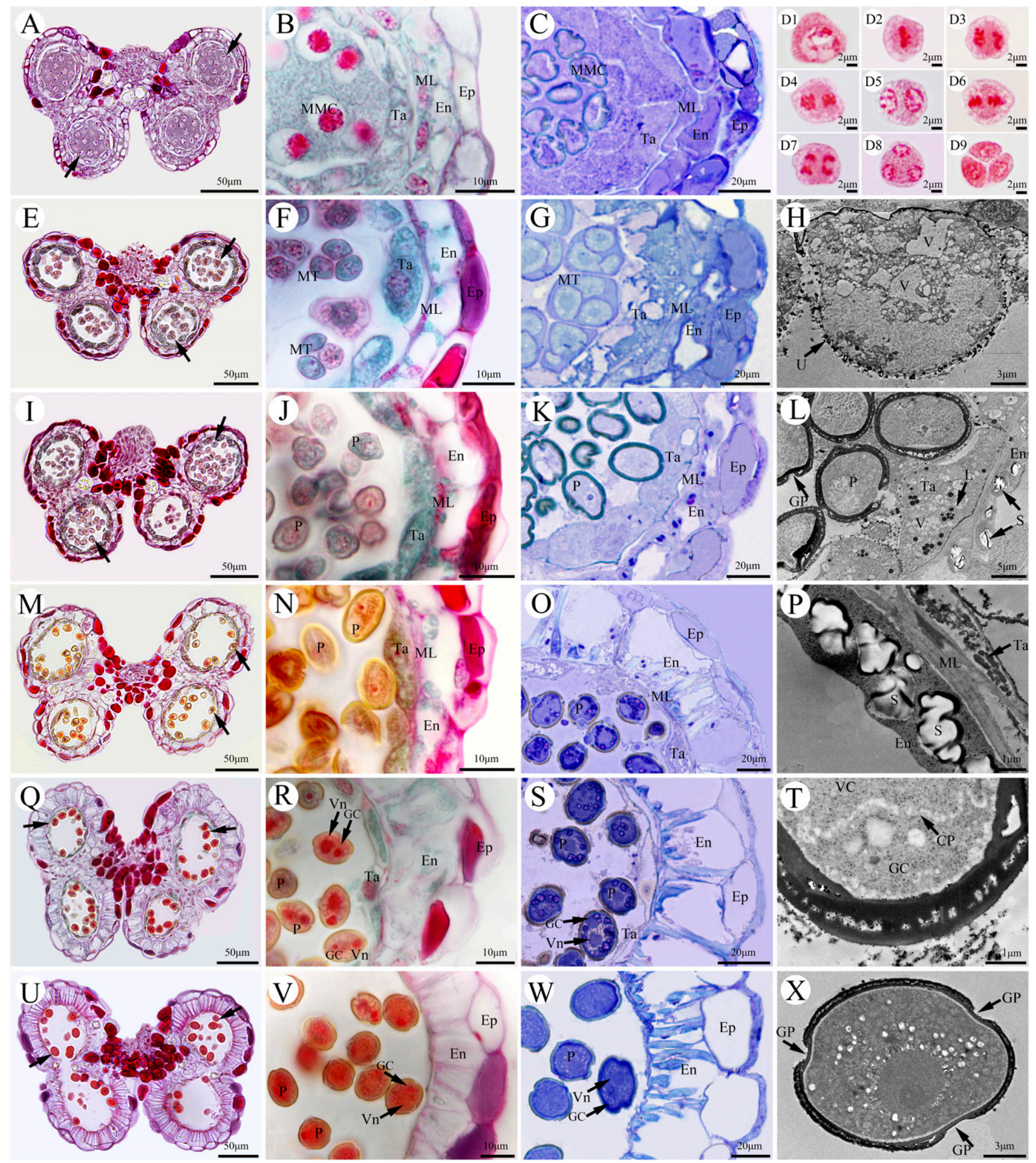

Fig. 2. The development of chinquapin anthers. (A-C) An anther at the microsporocyte stage. (D) Microsporocytes during meiosis. (D1) Microsporocytes during meiosis I prophase. (D2) Microsporocytes during meiosis I metaphase. (D3) Microsporocytes during meiosis I anaphase. (D4) Microsporocytes during meiosis I telophase. (D5) Microsporocytes during meiosis II prophase. (D6) Microsporocytes during meiosis II metaphase. (D7) Microsporocytes during meiosis II anaphase. (D8) Microsporocytes during meiosis II telophase. (D9) The tetrads. (E-G) An anther at the tetrad stage. (H) The vacuolated tapetal cell surrounded by Ubisch bodies at the tetrad stage. (I-K) An anther at the early microspore stage. (L) Early microspore stage with chloroplasts and chloroplast starch granules appearing in the endothecial cells and more lipids appearing in the tapetal cells. (M-O) An anther at the late microspore stage. (P) Degraded chloroplast and deformed starch grains. $(\mathbf{Q}-\mathbf{S})$ An anther at the early two-cell pollen stage. (T) Cell plate between the reproductive nucleus and vegetative nucleus. (U-W) An anther at the pollen maturation stage. (X) Pollen grain structure at the mature stage.

some anthers with multiple middle layers, the outermost layer may be retained for a long time, even until the anther maturation stage (Deng et al., 2018; Gao et al., 2015; Muniraja et al., 2018; Zhang et al., 2019; Zou et al., 2013). The middle layer has a secretory activity function and plays a key role in pollen development, which might help regu- late pollen fertility by changing the time of its own cell death (Cecchetti et al., 2017; Falasca et al., 2013). We observed a single-layer secretory tapetum in the chinquapin. At the 
tetrad phase, tapetal cells reached their maximum volume as the cell wall of the tapetum dissolved and many small vacuoles appeared. In the early stage of microspore development, the tapetum began to degenerate and was completely lost in mature anthers. The tapetum plays an important role in pollen development by providing nutrients, enzymes, and sporopollenin precursors for the development of microspores (Blackmore et al., 2007; Dong et al., 2005; Kim et al., 2016; Liu and Fan, 2013; Muniraja et al., 2018; Quilichini et al., 2014; Wei et al., 2015; Zhang et al., 2019). Transcriptomic studies have found that tapetal cell activity and subsequent programmed cell death are precisely controlled, and these processes are closely coordinated with pollen development (Huang et al., 2011). Premature or delayed degradation of the tapetum tends to result in male sterility (Deng et al., 2018; Li et al., 2006; Liu and Fan, 2013). Xie et al. (2005) reported that tapetal cells can be maintained close to flowering, and that the volume of tapetal cells increases significantly in sterile anthers. It is suggested that pollen abortion may also lead to the abnormal development of tapetum.

In the present study, we observed that the microspore mother cells underwent simultaneous meiosis, forming tetrads surrounded by callose. It is believed that callose circulation during microsporogenesis protects microspore mother cells and plays an important role in the release of microspores from the micro tetrads (Scott et al., 2004). The migration of microspore nuclei from the center to the edge of the cell might be related to the formation of large central vacuoles. At the early stage of microspore development, we found that the pollen wall was clearly visible, with three germ pores. Previous research has shown that the pollen wall retained its resistance to environmental stresses after anther dehiscence and functioned as a protective barrier for pollen grains (Blackmore et al., 2007; Li et al., 2010; Li and Zhang, 2010; Shi et al., 2011). The outer pollen wall has been shown to be crucial for the fertility of pollen and effective plant reproduction (Deng et al., 2018; Heslop-Harrison, 1968; Quilichini et al., 2015). Therefore, it is likely that defects in the outer pollen wall may lead to male sterility.

During pollen development, an abundance of nutrients, particularly starch grains and lipids, accumulates in pollen grains to ensure the availability of sufficient energy and material for pollen germination (Pacini, 1996). However, the metabolic pattern and distribution of starch and lipids vary in anthers of different plants. Clément et al. (1994) reported that the storage material in the mature pollen in Lilium was starch, and the starch transported to the anther was directly absorbed by the pollen. Xie et al. (2005) reported that the storage material in pollen in Chinese cabbage was lipids, but the initial form of nutrients transported in the anther wall was starch, which was transformed into lipids by tapetal cells for pollen absorption.
Liu et al. (2012) reported that the mature pollen in Ipomoea cairica stored starch and lipids, and that starch was converted into lipids for pollen absorption by tapetum.

In the present study, we observed the transformation and distribution of starch and lipids during the development of chinquapin anthers and found that the accumulation of nutrients during anther development of Castanea henryi had a certain regularity. During anther development, starch grains were detected in the endothecium and lipids appeared in the tapetum. Therefore, the nutrient transported to the locule was sugar, which was subsequently transformed to lipid drops by the tapetum and provided to pollen as a source of nutrients, which was similar to Ipomoea cairica (Liu et al., 2012). At the early microspore stage, the tapetal cytoplasm formed a large amount of lipids for pollen absorption, which was presumably related to the formation of large vacuoles. The mature pollen grains were rich in lipids and starch as nutrients, and the increase in starch suggested that pollen could convert lipid to starch. It can be seen that the accumulation of nutrients in the process of chinquapin anther development was totally different from that in the pollen containing only starch in Lilium and the pollen containing only lipid droplets in Chinese cabbage (Clément et al., 1994; Xie et al., 2005), and even from those containing starch and lipid droplets in Ipomoea cairica (Liu et al., 2012). This reflects the diversity of nutrient metabolism during pollen development in higher plants.

\section{Literature Cited}

Blackmore, S., A.H. Wortley, J.J. Skvarla, and J.R. Rowley. 2007. Pollen wall development in flowering plants. New Phytol. 174:483-498.

Borg, M., L. Brownfield, and D. Twell. 2009. Male gametophyte development: A molecular perspective. J. Expt. Bot. 60:1465-1478.

Brewbaker, J.L. 1967. The distribution and phylogenetic significance of binucleate and trinucleate pollen grains in the angiosperms. Amer. J. Bot. 54:1069-1083.

Cecchetti, V., D. Celebrin, N. Napoli, R. Ghelli, P. Brunetti, P. Costantino, and M. Cardarelli. 2017. An auxin maximum in the middle layer controls stamen development and pollen maturation in Arabidopsis. New Phytol. 213:11941207.

Clément, C., L. Chavant, M. Burrus, and C. Audran. 1994. Anther starch variations in Lilium during pollen development. Sex. Plant Reprod. 3:263-276.

Deng, Y., L. Liang, X. Sun, X. Jia, C. Gu, and J. Su. 2018. Ultrastructural abnormalities in pollen and anther wall development may lead to low pollen viability in jasmine (Jasminum sambac (L.) Aiton, Oleaceae). S. Afr. J. Bot. 114:6977.

Dong, X., Z. Hong, M. Sivaramakrishnan, M. Mahfouz, and D.P.S. Verma. 2005. Callose synthase (CalS5) is required for exine formation during microgametogenesis and for pollen viability in Arabidopsis. Plant J. 42:315-328.

Falasca, G., S. D’Angeli, R. Biasi, L. Fattorini, M. Matteucci, A. Canini, and M.M. Altamnra. 2013. Tapetum and middle layer control male fertility in Actinidia deliciosa. Ann. Bot. 112:1045-1055.
Fan, X., D. Yuan, J. Tang, X. Tian, L. Zhang, F. Zou, and X. Tan. 2015. Sporogenesis and gametogenesis in Chinese chinquapin (Castanea henryi (Skam) Rehder \& Wilson) and their systematic implications. Trees (Berl.) 29: 1713-1723.

Fan, X., D. Yuan, X. Tian, Z. Zhu, M. Liu, and H. Cao. 2017. Comprehensive transcriptome analysis of phytohormone biosynthesis and signaling genes in the flowers of Chinese chinquapin (Castanea henryi). J. Agr. Food Chem. 65:10332-10349.

Gao, C., D.Y. Yuan, B.F. Wang, Y. Yang, and Z.Q. Han. 2015. A cytological study of anther and pollen development in Camellia oleifera. Genet. Mol. Res. 14:8755-8765.

Goldberg, R.B., T.P. Beals, and P.M. Sanders. 1993. Anther development: Basic principles and practical applications. Plant Cell 5:1217-1229.

Heslop-Harrison, J. 1968. Pollen wall development. Science 161:230-237.

Huang, M.D., Y.I.C. Hsing, and A.H.C. Huang. 2011. Transcriptomes of the anther sporophyte: Availability and uses. Plant Cell Physiol. 52:1459-1466.

Kim, Y.J., M.G. Jang, L. Zhu, J. Silva, X. Zhu, J. Sukweenadhi, W.S. Kwon, D.C. Yang, and D. Zhang. 2016. Cytological characterization of anther development in Panax ginseng Meyer. Protoplasma 253:1111-1124.

Li, H. and D. Zhang. 2010. Biosynthesis of anther cuticle and pollen exine in rice. Plant Signal. Behav. 5:1121-1123.

Li, H., F. Pinot, V. Sauveplane, D. Werck-Reichhart, P. Diehl, L. Schreiber, R. Franke, P. Zhang, L. Chen, Y. Gao, W. Liang, and D. Zhang. 2010. Cytochrome P450 family member CYP704B2 catalyzes the \{omega\}-hydroxylation of fatty acids and is required for anther cutin biosynthesis and pollen exine formation in rice. Plant Cell 22:173-190.

Li, N., D.S. Zhang, H.S. Liu, C.S. Yin, X.X. Li, W.Q. Liang, Z. Yuan, B. Xu, H.W. Chu, J. Wang, T.Q. Wen, H. Huang, D. Luo, H. Ma, and D.B. Zhang. 2006. The rice tapetum degeneration retardation gene is required for tapetum degradation and anther development. Plant Cell 18:2999-3014.

Li, Y., D. Yuan, S. Xiao, Z. Zhu, T. Ye, X. Xiao, and F. Zou. 2019. Parent characteristics of different superior Castanea henryi clones and growth effects of their hybrid offspring. Nonwood. For. Res. 37:156-162.

Liu, L. and X.D. Fan. 2013. Tapetum: Regulation and role in sporopollenin biosynthesis in Arabidopsis. Plant Mol. Biol. 83:165-175.

Liu, R.S., Y.L. Qiu, D.M. Wei, H.H. Liu, X.Y. Zhu, H.Q. Tian, and J.A. Teixeira da Silva. 2012. Distribution of starch and neutral lipids in the developing anthers of lpomoea cairica. Ann. Bot. Fenn. 48:256-262.

Mert, C. 2010. Anther and pollen morphology and anatomy in walnut (Juglans regia L.). HortScience 45:757-760.

Mitsuda, N., M. Seki, K. Shinozaki, and M. OhmeTakagi. 2005. The NAC transcription factors NST1 and NST2 of Arabidopsis regulate secondary wall thickenings and are required for anther dehiscence. Plant Cell 17:2993-3006.

Muniraja, M., G. Vijayalakshmi, M.L. Naik, V.V. Bhaskar, and P.S.S.V. Khan. 2018. A developmental study on anther wall and pollen in Mangifera indica L. var. Beneshan (Anacardiaceae). S. Afr. J. Bot. 119:142-153.

Pacini, E. 1996. Types and meaning of pollen carbohydrate reserves. Sex. Plant Reprod. 9:362-366.

Quilichini, T.D., C.J. Douglas, and A.L. Samuels. 2014. New views of tapetum ultrastructure and 
pollen exine development in Arabidopsis thaliana. Ann. Bot. 114:1189-1201.

Quilichini, T.D., E. Grienenberger, and C.J. Douglas. 2015. The biosynthesis, composition and assembly of the outer pollen wall: A tough case to crack. Phytochemistry 113: $170-182$.

Scott, R.J., M. Spielman, and H.G. Dickinson. 2004. Stamen structure and function. Plant Cell 16:S46-S60.

Shi, J., H. Tan, X.H. Yu, Y. Liu, W. Liang, K. Ranathunge, R.B. Franke, L. Schreiber, Y. Wang, G. Kai, J. Shanklin, H. Ma, and D. Zhang. 2011. Defective pollen wall of required for anther and microspore development in rice and encodes a fatty acyl carrier protein reductase. Plant Cell 23:2225-2246.

Wei, D., H. Xu, and R. Li. 2015. Dynamics of polysaccharides and neutral lipids during an- ther development in castor (Ricinus communis). J. Amer. Soc. Hort. Sci. 140:356-361.

Wilson, Z.A. and D.B. Zhang. 2009. From Arabidopsis to rice: Pathways in pollen development. J. Expt. Bot. 60:1479-1492.

Xie, C.T., Y.H. Yang, Y.L. Qiu, X.Y. Zhu, and H.Q. Tian. 2005. Cytochemical investigation of genic male-sterility in Chinese cabbage. Sex Plant Reprod. 18:75-80.

Xiong, H., H. Sun, F. Zou, X. Fan, G. Niu, and D. Yuan. 2018. Micropropagation of chinquapin (Castanea henryi) using axillary shoots and cotyledonary nodes. HortScience 53:1482-1486.

Yang, C., G. Vizcay-Barrena, K. Conner, and Z.A. Wilson. 2007. MALE STERILITY1 is required for tapetal development and pollen wall biosynthesis. Plant Cell 19:3530-3548.

Yang, S., P. Li, H. Bao, and H. Tian. 2018. Cytological features of developing anthers in rose balsam. J. Amer. Soc. Hort. Sci. 143:95-100.

Zhang, D., Q. Chen, Q. Liu, F. Liu, L. Cui, W. Shao, S. Wu, J. Xu, and D. Tian. 2019. Histological and cytological characterization of anther and appendage development in Asian lotus (Nelumbo nucifera Gaertn.). Intl. J. Mol. Sci. 20:1015.

Zhu, Z., D. Yuan, X. Fan, X. Zhang, L. Tan, J. Tang, D. Liu, C. Li, and X. Sun. 2016. Effects of plant growth regulator on flower bud sex differentiation and fruiting branch growth of Castanea henryi. J. Cent. S. Univ. For. Technol. 36:63-66.

Zou, F., S.J. Guo, H. Xiong, P. Xie, W.J. Lv, and G.H. Li. 2013. A morphological and histological characterization of male flower in chestnut (Castanea) cultivar 'Yanshanzaofeng'. Adv. J. Food Sci. Technol. 5:1192-1197. 